\title{
Chemotaxis toward carbohydrates and peptides by mixed ruminal protozoa when fed, fasted, or incubated with polyunsaturated fatty acids
}

\author{
H. L. Diaz, ${ }^{1}$ S. K. R. Karnati, ${ }^{1}$ M. A. Lyons, ${ }^{2}$ B. A. Dehority, and J. L. Firkins ${ }^{3}$ \\ Department of Animal Sciences, The Ohio State University, Columbus 43210
}

\begin{abstract}
In contrast to the well-characterized chemotaxis and migratory behavior between the dorsal and ventral locations of the rumen by isotrichids, we hypothesized that chemotaxis toward soluble nutrients maintains entodiniomorphid protozoa in the particulate fraction. The objectives of these experiments were to compare the dose-responsive chemotaxis (1) toward different glucose concentrations when ruminal samples were harvested from fed versus fasted cows; (2) toward increasing concentrations of glucose compared with xylose when protozoa were harvested from a fed cow; (3) toward peptides of bacterial, protozoal, and soy origin; and (4) toward glucose when mixed ruminal protozoa were previously incubated for 0,3 , or $6 \mathrm{~h}$ in the presence of emulsified polyunsaturated fatty acids (PUFA; Liposyn II, Hospira, Lake Forest, IL). In experiment 1 , isotrichid protozoa decreased chemotaxis toward increasing glucose concentration when cows were fasted. Entodiniomorphids exhibited chemotaxis to similar concentrations of glucose as did isotrichids, but to a lesser magnitude of response. In experiment 2, xylose was chemotactic to both groups. Xylose might draw fibrolytic entodiniomorphid protozoa toward newly ingested feed. In contrast, even though isotrichids should not use xylose as an energy source, they were highly chemoattracted to xylose. In experiment 3, entodiniomorphids were not selectively chemoattracted toward bacterial or protozoal peptides compared with soy peptides. In experiment 4, despite isotrichid populations decreasing in abundance with increasing time of incubation in PUFA, chemotaxis to glucose remained unchanged. In contrast, entodiniomorphids recovered chemotaxis to glucose with increased time of PUFA incubation. Current results support isotrichid chemotaxis to sugars but also our hypothesis that a more moderate
\end{abstract}

Received August 27, 2013.

Accepted November 25, 2013.

${ }^{1}$ Current address: Procter and Gamble, 8700 Mason-Montgomery Rd, Mason, $\mathrm{OH} 45040$.

${ }^{2}$ Current address: USDA ARS Plum Island Animal Disease Center, Plum Island, NY 11957.

${ }^{3}$ Corresponding author: firkins.1@osu.edu chemotaxis toward glucose and peptides explains how they swim in the fluid but pass from the rumen with the potentially digestible fraction of particulates.

Key words: rumen protozoa, chemotaxis, sugars, peptides

\section{INTRODUCTION}

In ruminants, microbial crude protein is typically the major source of metabolizable protein resulting from the supply and profile of amino acids absorbed from the intestine (NRC, 2001). However, the amount of microbial protein that passes out of the rumen depends on nutrient availability and the efficiency of use of these nutrients by rumen microbes (Bach et al., 2005). Increasing the ruminal passage rate increases the efficiency of growth independent of substrate supply (Dijkstra et al., 1998). Sylvester et al. (2005) and Karnati et al. (2007) suggested that protozoa passed out of the rumen at approximately the same rate as the solid-phase digesta. Because isotrichid protozoa (those in the family Isotrichidae, having cilia over their entire cell) migrated dorsally upon feeding or even at the same feeding time but when feed was deliberately withheld (Dehority and Tirabasso, 1989), isotrichids must coordinate migration (net movement) with chemotaxis (swimming toward a concentration gradient). Thus, we reasoned that simple protozoal sequestration in the rumen is probably overly simplistic and also does not match the nonmigratory behavior of the more numerically abundant entodiniomorphids (those in the order Entodiniomorphida, partly differentiated by their primary location of cilia at the anterior end of the cell).

Hook et al. (2012) emphasized sequestration of ruminal entodiniomorphids, potentially through particulate entrapment and attachment to particles, which has long been held as a mechanism to enable growth rates expected to be slower than passage of ruminal fluid (Bauchop and Clarke, 1976). In contrast, Dehority (1984) noted little evidence for long-term physical attachment. Orpin (1985) described potential adherence and feed occlusion to explain attraction to particles but also suggested chemotaxis as an important retention factor. In the current study, we theorized that 
glucose and xylose might be important chemosensory components directing fibrolytic entodiniomorphid protozoa to their preferred substrates. The objective of experiment 1 was to compare dose-responsive chemotaxis toward different glucose concentrations by both isotrichids and entodiniomorphs, with the hypothesis that ruminal samples collected within $3 \mathrm{~h}$ after feeding a cow, compared with fasting for $12 \mathrm{~h}$, would reduce chemotaxis, particularly for isotrichids. In experiment 2 , the objective was to compare relative chemotaxis toward increasing concentrations of glucose or xylose when protozoa were harvested from a fed cow. Our hypothesis was that xylose would be less chemotactic than glucose, especially for the highly chemoresponsive isotrichids (Murphy et al., 1985). Many entodiniomorphids are active hemicellulolytics, whereas isotrichids probably use little xylose for energy (Dehority, 2003).

Protozoa are known to contribute extensively to bacterial predation, ruminal proteolysis, and intraruminal recycling of microbial protein (Firkins, 1996; Walker et al., 2005; Firkins et al., 2007). Early studies suggested growth stimulation by protozoa when exposed to protozoa extract (Jarvis and Hungate, 1968). Nonrumen ciliates that predate bacteria are consistently chemoattracted to bacterial peptides or gradients of amino acids that are in high concentration in bacterial proteins (Kohidai et al., 2003b). Although growth of Entodinium caudatum was stimulated by cell-free extracts of bacteria, this response was enhanced when the extracts were adsorbed to charcoal that was subsequently consumed (Onodera and Henderson, 1980); whether this engulfment process is nonselective or enhanced by bacterial peptides is not known. The objective of experiment 3 was to assess dose-responsive chemotaxis by entodiniomorphids and isotrichids toward peptides of bacterial, protozoal, and soy origin. We hypothesized that protozoa would be more chemoattracted to peptides from bacteria, their main prey, than those of protozoal or soy origin.

Protozoa are inhibited by unsaturated fat and medium-chain fatty acids (Firkins and $\mathrm{Yu}, 2006$ ), but a direct mechanism has not been well characterized other than an expectation for interference in membrane function (Reveneau et al., 2012). Ruminal protozoa are known to incorporate high concentrations of PUFA and biohydrogenation intermediates in their membranes (Firkins et al., 2008). Chemotactic responsiveness in the nonrumen ciliate genus Tetrahymena seems localized at the cilial membrane (Leick and Chen, 2004). Lysophosphatidic acid, which could be derived from hydrolysis of plant phospholipids, is a common chemoattractant in Tetrahymena spp. (Lampert et al., 2011) and might also interrupt chemotaxis by ruminal protozoa to glucose. In experiment 4, we hypothesized that prolonged exposure to fat would disrupt receptorbased chemotaxis toward glucose and be increasingly inhibitory when mixed ruminal protozoa were previously incubated in the presence of $0,0.5,1.0$, or $2.0 \%$ (vol/vol) emulsified PUFA and phospholipids (Liposyn II, Hospira, Lake Forest, IL) as exacerbated with prolonged time $(0,3$, and $6 \mathrm{~h}$ of incubation).

Our comprehensive objectives were to design appropriate assays and systematically assess source and dose-dependent chemosensory responses to sugars, peptides, and PUFA by mixed ruminal entodiniomorphid compared with isotrichid protozoa.

\section{MATERIALS AND METHODS}

\section{Experiment 1: Timing of Feeding and Chemotaxis to Glucose}

In experiment 1, rumen contents from 2 rumen-cannulated Holstein cows were collected $12 \mathrm{~h}$ after withholding feed overnight or were simultaneously collected from 2 different cows at $3 \mathrm{~h}$ after feeding a diet consisting of mixed forage and grain (50:50). Samples were taken at approximately the same time and from the same cows for replicate inocula. Rumen contents were collected from different sites of the rumen to obtain a representative sample of all the rumen compartments and filtered using 2 layers of cheesecloth, which reduces entrapment of protozoa with particles (Dehority, 1984). Animals were maintained in accordance with The Ohio State University's animal care and use guidelines. The rumen fluid was transported to the laboratory in an insulated vessel previously warmed by filling with $39^{\circ} \mathrm{C}$ water. Once in the laboratory, rumen fluid from both cows was pooled per feeding treatment. After incubation for $30 \mathrm{~min}$ to allow flotation of plant particles (hereafter termed flocculation), the top was aspirated with a pipette using suction.

For the chemotaxis assay that was used in this and all subsequent studies (Figure 1), $20 \mathrm{~mL}$ of flocculated rumen fluid was pipetted into each of a series of $50-\mathrm{mL}$ beakers containing 4 capillary tubes ( $75 \mathrm{~mm}$ length, 1.5 $\mathrm{mm}$ o.d., $1.0 \mathrm{~mm}$ i.d.) per treatment. The treatments in the capillary tubes included 2 empty, unsealed (UN) capillary tubes that were inserted into each beaker; upon entry, they drew up ruminal fluid to help standardize for protozoal abundance or diversity of populations among beakers that could occur randomly or as a result of preincubation treatments (as in experiment 4). Statistically, this correction decreases variance associated with among-beaker differences, allowing insertion times to be staggered and permitting more careful handling of a manageable number of sealed capillary tubes across the series of beakers used in each experiment. 
Fill capillary tubes with different glucose concentrations $(\mathrm{mM})$ in $0.9 \%$ saline

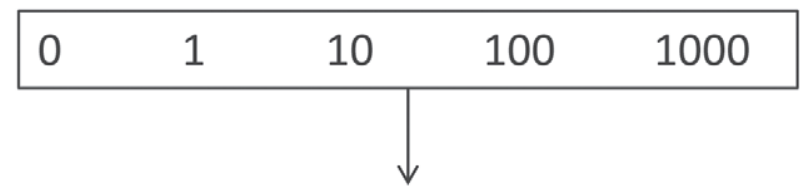

Seal top with clay

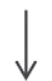

After rumen fluid added, gently insert 2 glucose treatment tubes per single beaker per time (0 or $20 \mathrm{~min}$ )

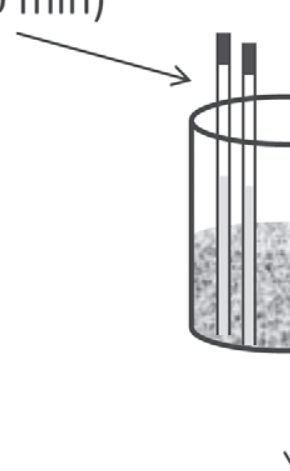

Empty and unsealed (UN) capillary tubes

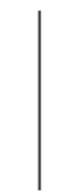

Do not seal

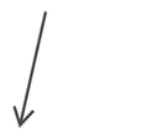

2 tubes per beaker
Collect rumen fluid from 2 cows fasted for $12 \mathrm{~h}$ or from 2 cows $3 \mathrm{~h}$ after feeding, combine per feeding treatment<smiles>C1C[Te]C1</smiles>

Bubble fluid and flush head space with $\mathrm{N}_{2}$, flocculate for 30 min at $39^{\circ} \mathrm{C}$, aspirate

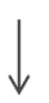

After stirring, pipette 20 $\mathrm{mL}$ with widemouth pipette into beakers, flush head space with $\mathrm{N}_{2}$

\section{After 0 (immediately after insertion) or $20 \mathrm{~min}$ of incubation inside a $39^{\circ} \mathrm{C}$ oven, remove} capillary tubes, carefully wipe excess external fluid with a Kimwipe, aspirate internal fluid from duplicate tubes into a pooled container, and add formalin to preserve until counting

Figure 1. The chemotaxis assay for preparation of capillary tubes for insertion into beakers immediately after transfer of flocculated rumen fluid. The insertion of capillary tubes was staggered over time, and the design balanced for the same average time among treatments for the time interval between rumen fluid collection and insertion of capillary tubes. The empty and unsealed (UN) capillary tubes were used to adjust for among-beaker differences in protozoal counts.

In experiment 1 , glucose $(\mathbf{G})$ was dissolved in saline to provide $1,10,100$, or $1,000 \mathrm{~m} M$, corresponding with G1, G10, G100, and G1000 treatment designations, respectively. After treatment addition, the exteriors of capillary tubes were carefully wiped with a tissue to remove exterior but not interior fluid, and the tubes were sealed at the top (but not bottom) to stabilize capillary action but permit a gradient between the bottom of the capillary tube and the surrounding rumen fluid in the beakers. Murphy et al. (1985) used $0.76 M$ glucose (similar to our $1 M$ highest treatment). Along with the UN tubes, 4 tubes per treatment were placed in each beaker in a tent-like arrangement. Two capillary tubes were removed from the beakers at $0 \mathrm{~min}$, and the other 2 were removed after a 20-min incubation. This time is consistent with Orpin's (1985) measurements for peak association of rumen ciliates with plant particulate matter and should reduce potential desensitization of motility that has been detected with nonrumen ciliates (Lampert et al., 2011). Treatments were staggered in a sequence that allowed proper 20-min timing among all beakers but still allowed us to balance this staggered arrangement such that all treatments had the same average time after rumen fluid was collected. After carefully wiping the outside to remove exterior protozoa but not draw out interior protozoa, the 2 capillary tubes were aspirated into a combined test tube preserved with $50 \%$ formalin. Fluid was combined to reduce variation from slight differences in volumes among capillary tubes.

Two $40-\mu \mathrm{L}$ aliquots of the preserved capillary tube contents were transferred to a slide, which was counted, rotated, and counted again using a grid (Dehority, 1984). A saline control at time zero was used as a blank correction for protozoa that entered tubes while they 
were being inserted into the beakers. The 0 -min capillary tubes had random counts for all treatments, so we used a single 0-min average count to correct for random uptake resulting from insertion of the tubes in all subsequent experiments. Data are presented as total protozoal cells inside the combined duplicate capillary tubes after 20 min after subtracting the 0-min counts in $80 \mu \mathrm{L}$ (i.e., the 2 counts from $40-\mu \mathrm{L}$ aliquots were summed to reduce error). The original model included effects of 3 inocula replications (random block effects), feeding time (fasted vs. fed), and treatment in the capillary tubes (UN tubes and sealed capillary tubes containing saline, G1, G10, G100, or G1000). Data were analyzed using the Mixed procedure of SAS (version 8.2; SAS Institute Inc., Cary, NC). Treatments were compared with Fisher's protected least significant difference (LSD) because of our resultant conclusion that isotrichid uptake into sealed capillary tubes interfered with entodiniomorphid uptake, thus disturbing the expected dose-response. Although we optimized and standardized the chemotaxis assay, protozoal counts are associated with amplified variation that includes differences among animals, samples, settling within samples, and random error (Oldick and Firkins, 2000; Skillman et al., 2006). To protect against Type II error, the threshold for significance was uniformly applied at $P<0.10$. However, when $0.05<P$ $<0.10$, we declared the highest $P$-value from the multiple comparisons but maintained a consistent $P>0.10$ cutoff for rejection of significance.

\section{Experiment 2: Comparison of Glucose and Xylose as Chemoattractants}

Ruminal fluid was collected $3 \mathrm{~h}$ after feeding, and the protocol was similar to that in experiment 1 (Figure 1). After flocculation, $20 \mathrm{~mL}$ of ruminal fluid was placed in beakers containing capillary tubes with glucose concentrations as in experiment 1. Similarly, xylose $(\mathbf{X})$ was added at comparable molar concentrations designated $\mathrm{X} 1, \mathrm{X} 10, \mathrm{X} 100$, and $\mathrm{X} \mathbf{1 0 0 0}$, respectively, to designate the millimolarity. Capillary tubes were inserted into beakers, withdrawn, and counted as described in experiment 1 . The original model for 20 -min counts in capillary tubes (corrected for $0 \mathrm{~min}$ ) included effects of 3 inocula replications (random block effects) and treatment. Data were analyzed using the Mixed procedure of SAS (version 8.2; SAS Institute Inc.). Treatments were compared with Fisher's protected LSD, as explained for experiment 1.

\section{Experiment 3: Chemotaxis to Peptides of Soy, Protozoal, or Bacterial Origin}

In experiment 3, we assessed chemotaxis toward peptides from soybean protein (soy), bacteria (BP), and protozoa (PP; Figure 2). To harvest bacteria and protozoa, ruminal fluid was collected as described for experiment 1. Protozoa and bacteria were harvested using a procedure adapted from that outlined by Sylvester et al. (2005). Samples were filtered and dialyzed in $10-\mu \mathrm{m}$ filter bags; bacteria were recovered from those filtrates and dialysates, combined, washed, and concentrated using differential centrifugation. After brief sonication to resuspend the protozoal and bacterial pellets, supernatants were analyzed for protein using the bicinchoninic acid assay (BCA, Pierce, Rockford, IL). Then, aliquots were hydrolyzed with proteinase K (Pierce), incubated in $5 \%$ ( $\mathrm{vol} / \mathrm{vol}$ ) of perchloric acid, and centrifuged to collect peptides (Sylvester et al., 2004). Proteinase K was chosen to simulate the generation of peptides in the rumen because it is a broad-spectrum serine protease of microbial origin.

Two replicate capillary tubes per treatment per respective beaker were unfilled and unsealed (UN) or filled with 0 (saline control) before sealing at the top, as shown in Figure 1. Protozoal and bacterial peptides and the soy protein isolate (MP Biomedicals LLC, Solon, $\mathrm{OH}$ ) were analyzed for protein using BCA as described previously and resuspended in $0.9 \% \mathrm{NaCl}$ to provide solutions of $125,250,500,750$, or $1,000 \mathrm{mg} / \mathrm{L}$ of soluble peptides, which were drawn into capillary tubes before sealing. The doses were based on concentrations of soluble peptides in the rumen, varying from 200 to $1,200 \mathrm{mg} / \mathrm{L}$ immediately after feeding (Russell, 2002). After sealing, the filled tubes were placed in 3 replicate beakers with $20 \mathrm{~mL}$ of rumen fluid recovered from a dairy cow $3 \mathrm{~h}$ after feeding. In contrast to experiments 1 and 2, residuals followed a skewed distribution, so triplicates of 20-min counts (adjusted for 0-min counts) were normalized to $\log$ base 10 . Data were analyzed as a randomized complete block (3 replicate incubations; random effect) for a $3 \times 6$ factorial arrangement $(3$ peptide sources, 6 peptide concentrations) using the Mixed procedure of SAS. Main effects of peptide source and peptide concentration were compared when their interaction was not significant $(P>0.10)$. The rationale for declaring this cutoff was explained for experiment 1. For peptide source, Fisher's protected LSD was used to compare means. Preplanned contrasts were used to determine linear $(\mathbf{L})$, quadratic $(\mathbf{Q u})$, cubic $(\mathbf{C u})$, and quartic $(\mathbf{Q r})$ responses to increasing concentration of peptides (corrected for unequal spacing). When the interaction of peptide source and peptide concentration was significant, these contrasts were performed per peptide source (soy, BP, or PP). When source $\times$ treatment interactions were $P>0.10$, these contrasts were performed for peptide concentration from the main effect means (averaged over peptide source). The UN treatments were not used in any statistical comparisons 


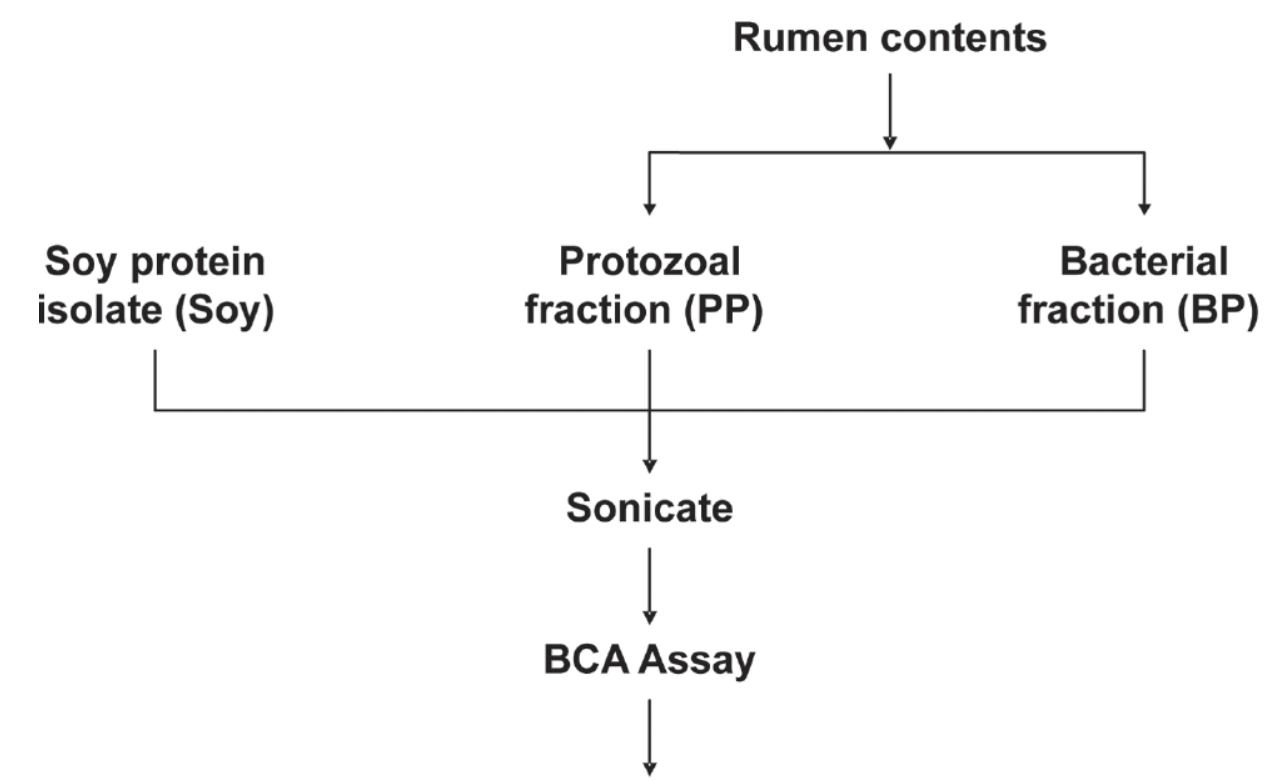

Digestion with Proteinase $\mathrm{K}$ at $55^{\circ} \mathrm{C}$ for $3 \mathrm{~h}$

Treat with $\mathrm{HClO}_{4}(5 \% \mathrm{vol} / \mathrm{vol})$ at $0^{\circ} \mathrm{C}$ for $30 \mathrm{~min}$

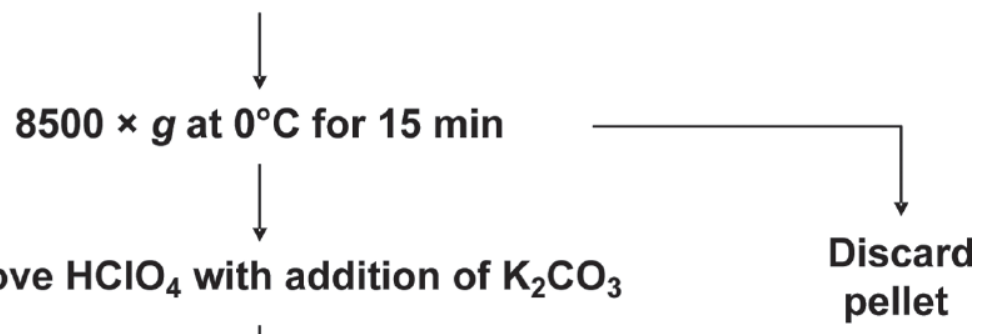

Remove $\mathrm{HClO}_{4}$ with addition of $\mathrm{K}_{2} \mathrm{CO}_{3} \quad$ pellet

$8500 \times g$ at $0^{\circ} \mathrm{C}$ for $15 \mathrm{~min}$

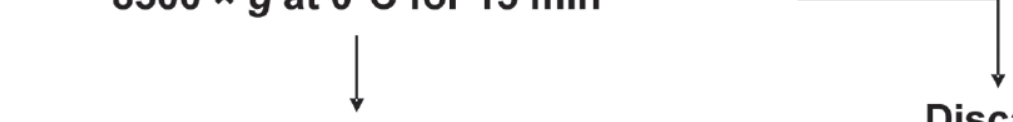

Freeze soluble fraction until analysis

Discard

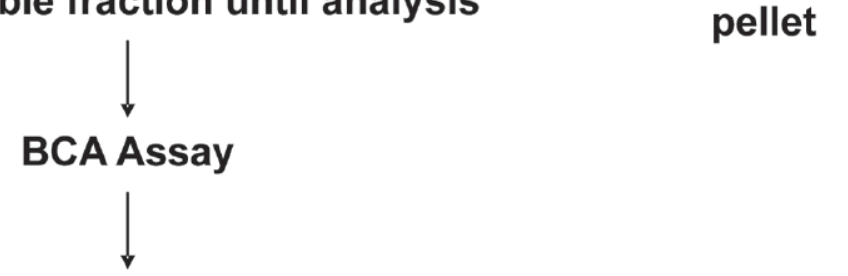

Prepare 0, 125, 250, 500, 750 and $1000 \mathrm{mg} / \mathrm{L}$

in $0.9 \%$ saline for each peptide source

Figure 2. The procedure used to hydrolyze different protein sources to peptides in experiment 3. Protozoal protein (PP) and bacterial protein (BP) were collected using filters and dialysis using the procedure outlined by Sylvester et al. (2004). Then, the different protein sources were hydrolyzed, precipitates removed, and soluble peptides quantified for subsequent usage in the chemotaxis assay. BCA = bicinchoninic acid. 
but were shown for comparisons of entodiniomorphid and isotrichid counts in sealed capillary tubes relative to their respective UN counts.

\section{Experiment 4: Preincubation in PUFA and Chemotaxis to Glucose}

Ruminal fluid was collected $3 \mathrm{~h}$ after feeding and flocculated as described previously for experiment 1 . With repeated mixing, $20 \mathrm{~mL}$ of ruminal fluid was placed in beakers and incubated in an anaerobic chamber for 0,3 , or $6 \mathrm{~h}$ in the presence of $0,0.5,1.0$ or $2.0 \%$ (vol/vol) emulsified lipid including PUFA (Liposyn II $20 \%$, Hospira). After preincubation, capillary tubes that were filled with either saline or $1,000 \mathrm{~m} M$ glucose (to maximize treatment response, based on results from experiments 1 and 2) in saline or unfilled and unsealed (UN), were placed into the beakers containing the preincubated rumen fluid. Triplicates of 20-min counts (adjusted for 0-min counts) were counted as in experiment 1 and counts normalized to log base 10, as justified for experiment 3. Data were analyzed using the Mixed procedure of SAS (version 8.2; SAS Institute Inc.) in a randomized complete block (3 replicate incubations; random effects). We first performed ANOVA only on the $\log _{10}$ counts in the UN capillary tube treatments at 3 and $6 \mathrm{~h}$ to determine the effects of time and the interaction of time with PUFA on protozoal counts. Preplanned contrasts were used to determine linear L, $\mathrm{Qu}, \mathrm{C}$, and $\mathrm{Qr}$ responses to increasing concentration of PUFA (corrected for unequal spacing). When the treatment $\times$ time interaction was $P<0.10$, polynomial contrasts for PUFA concentration were compared for each time; when the interaction was $P>0.10$, contrasts were compared for the main effect of time (averaged over 3 and $6 \mathrm{~h}$ of incubation). The rationale for this statistical cutoff was provided for experiment 1 . To assess the effects of PUFA on chemotaxis after accounting for potential treatment or time effects on protozoal counts in the beakers, the sealed capillary tube counts were covariate-adjusted for the respective $\log _{10}$ counts of the respective UN capillary tube treatments and analyzed for a $4 \times 2$ factorial arrangement of PUFA beaker treatments $(0,0.5,1.0$, and $2.0 \%$ per volume) and 2 capillary tube treatments (saline and glucose). Main effect means for PUFA beaker treatments (averaged over sealed capillary tube treatments) and main effect means for saline and glucose sealed capillary tube treatments (averaged over PUFA beaker treatments) were assessed when no interactions were detected $(P>$ $0.10)$. Simple means were presented by capillary tube treatment when interactions between PUFA $\times$ capillary treatment were detected $(P<0.10)$. Respective means for beaker treatments were compared by polynomial contrasts, and respective means for sealed capillary tube treatments were compared by a protected LSD.

\section{RESULTS AND DISCUSSION}

When developing our chemotaxis assay (Figure 1), we tried various approaches that could be systematically applied to multiple treatments while allowing standardization and replication to provide adequate statistical power. We noted that saline improved repeatability compared with distilled water for diluents of the chemoattractants in capillary tubes. We chose not to use clarified rumen fluid as a diluent because it would contain varying concentrations of the chemoattractants we were planning to evaluate. We consistently observed that maintaining the temperature near $39^{\circ} \mathrm{C}$ was critical to maintain motility of a high proportion of ciliates. We also noted that particulate matter increased variability among the 0 -min counts unless we flocculated the rumen fluid while warming the rumen fluid to $39^{\circ} \mathrm{C}$. Although anaerobiosis and $\mathrm{pH}$ control were critical during preincubations, anaerobiosis during the 20-min incubation had no noticeable effect when evaluated separately, and bubbling $\mathrm{CO}_{2}$ consistently disturbed the capillary tube arrangements in beakers. Mah (1964) noted minimal effect on motility at 20 min in Ophryoscolex cultures (entodiniomorphids) unless the bubbled gas had $10 \% \mathrm{O}_{2}$. Isotrichids probably are more aerotolerant and potentially increase glucose uptake with minute $\mathrm{O}_{2}$ concentrations (Williams and Coleman, 1997). Finally, we improved the technique by careful insertion of the sealed capillary tubes into beakers to reduce uptake of ruminal fluid (which was visually noticeable) and, upon extraction of the tubes, by careful wiping of the tip to remove exterior ruminal fluid without absorbing interior fluid.

\section{Experiment 1: Timing of Feeding and Chemotaxis to Glucose}

Isotrichids in the rumen primarily metabolize sugars of glucose and(or) fructose composition and are known to be chemotactic toward them (Dehority, 2003), but we expected chemotaxis to be blunted after isotrichids fill with storage polysaccharide (Dehority and Tirabasso, 1989). Isotrichids synchronize migration with meal frequency; moreover, increasing the number of meals seems to decrease the amplitude of changes in counts, apparently distributing the isotrichids (Abe et al., 1981). In experiment 1 (Figure 3), we observed an interaction between treatment and feeding status for isotrichids $(P$ $<0.01$ ). For both fasted and fed protozoa, chemotaxis by isotrichids to $100 \mathrm{~m} M$ glucose was greater $(P<0.05)$ than that to lower glucose concentrations. Chemotaxis 
was greatest for $1,000 \mathrm{~m} M$ glucose when protozoa were collected from the fasted cow but declined $(P<0.05)$ for $1,000 \mathrm{~m} M$ compared with $100 \mathrm{~m} M$ when the cow was fed. Greater swimming to the lower concentration $(100 \mathrm{~m} M)$ does not appear to directly support our hypothesis for desensitization of sugar receptors. The original fluid was collected from several locations in the rumen readily accessible through the cannula but not taken by scraping the layer of isotrichids that likely were sedimenting to the ventral rumen and reticulum, which might be more likely to repress chemotaxis postfeeding. We realize that glucose would not be expected to exceed $25 \mathrm{~m} M$ in vivo (Piwonka et al., 1994), but the glucose gradient would decrease significantly for protozoa in beakers with increasing distance from the open end of the capillary tubes and as the glucose inside the tubes is depleted by the microbes entering the capillary tubes.

In contrast to that for isotrichids, we detected no interaction between treatment and feeding for entodiniomorphids $(P>0.10)$ in experiment 1 (data not shown), probably because of the relatively high variability (means ranging from 9 to 38 counts with a pooled SE of 8.2; data not shown). Therefore, results from experiments 1 and 2 for fed cows were merged to add power; all statistics were the same except that experiment was added as a random block. When data for fed cows among both experiments were merged (Figure $4)$, the greatest chemotaxis occurred for isotrichids at $100 \mathrm{~m} M$ of glucose $(P<0.06$; greater than counts for all other concentrations); in contrast, this concentration had the numerically lowest entodiniomorphid counts,

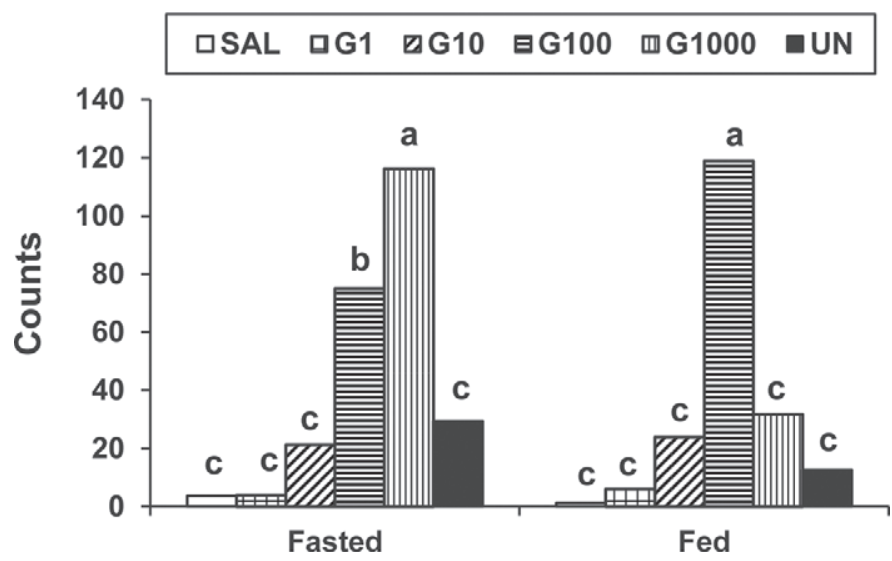

Figure 3. Isotrichid counts in capillary tubes filled with saline (SAL) or saline plus glucose (G) at 1, 10, 100, or $1000 \mathrm{mM}$ before sealing (G1 to G1000) or in empty and unsealed (UN) capillary tubes. Rumen fluid was collected $12 \mathrm{~h}$ after withholding feed (Fasted) or $3 \mathrm{~h}$ after feeding (Fed) a diet consisting of mixed forage and grain (50:50) in experiment 1 . The pooled SE was 12.0 counts. There was a treatment $\times$ time interaction $(P<0.01)$. ${ }^{\mathrm{a}-\mathrm{c}}$ Means with unlike letters are different $(P<0.05)$. which were less than $(P<0.09)$ respective counts in tubes containing 10 and 1,000 $\mathrm{m} M$ glucose. The lower entodiniomorphid counts in $100 \mathrm{~m} M$ glucose could be a result of (1) faster swimming (Diaz et al., 2014) and rapid depletion of the glucose gradient by the isotrichids or (2) rapid production of storage polysaccharide and settling of isotrichids to the bottom of the capillary tube (but retention because of capillary action), which might have physically prevented entry by entodiniomorphids. Competition for narrow channels leading toward chemotactic gradients has been described for nonrumen ciliates (Wang et al., 2005). Although the counts relative to the UN tubes were uniformly lower for entodiniomorphids than for isotrichids, the comparison of the relative dose responsiveness (except for $100 \mathrm{~m} M$ glucose) supports chemotaxis to similar glucose gradients as for the highly chemotactic isotrichids. The lack of feeding interaction and moderate dose-responsiveness for entodiniomorphids support relatively constant chemotaxis to remain associated with feed particles.

\section{Experiment 2: Comparison of Glucose and Xylose as Chemoattractants}

Isotrichids (Figure 5A) were numerically 2-fold more chemotactic toward xylose than toward glucose, with the reverse generally noted for entodiniomorphids (Figure 5B). Counts in capillary tubes with $1 M$ glucose or $1 M$ xylose were several-fold greater than UN for isotrichids but several-fold less than UN for entodiniomorphids, supporting the primary reliance on sugars in isotrichid ecology. Because isotrichids probably do not ferment xylose (Dehority, 2003), the greater chemotaxis toward 1,000 $\mathrm{m} M$ xylose than 1,000 $\mathrm{m} M$ glucose by isotrichids was contrary to our hypothesis but suggests a nonspecific receptor for chemotactic responses. If the isotrichids do not ferment xylose, it seems unlikely that they dissipated the xylose gradient for entodiniomorphids. Thus, that chemotaxis by entodiniomorphids to xylose did not even exceed the saline control for X1000 $(P>0.10)$ was also unexpected. Free glucose in forages or glucose release from amylolytic attack of starch might lead to locally higher concentrations of glucose in rumen fluid, whereas our results do not support xylose as a major chemotactic molecule that draws fibrolytic entodiniomorphids toward nonstarch particulate matter in the rumen. Epidinium caudatum consumed purified cellulose particles more extensively than purified xylan (Michalowski et al., 2001). Even fibrolytic protozoa engulf starch granules (Belzecki et al., 2004), and the fibrolytics Ep. caudatum (Coleman and Laurie, 1974) or Polyplastron multivesiculatum (Coleman and Laurie, 1977) both consumed glucose more rapidly than the amylolytic Entodinium caudatum in their studies. 


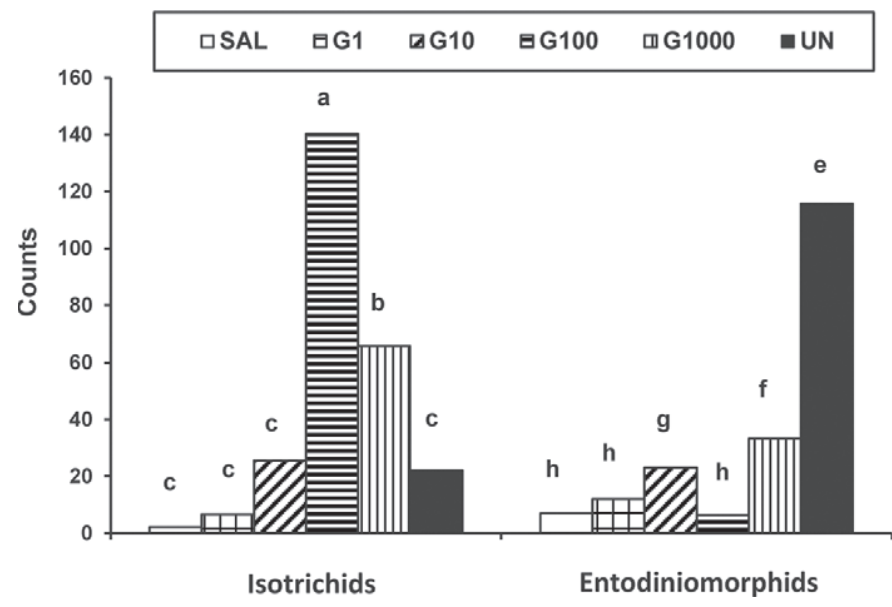

Figure 4. Counts of mixed isotrichids and entodiniomorphids in capillary tubes filled with saline (SAL) or saline containing glucose $(\mathrm{G})$ at 1, 10, 100 and 1,000 $\mathrm{mM}$ before sealing (G1 to G1000) or in empty and unsealed (UN) capillary tubes. Rumen fluid was collected $3 \mathrm{~h}$ after feeding a diet consisting of mixed forage and grain (50:50). Data from experiments 1 and 2 were combined. There was no block $\times$ treatment interaction $(P>0.10) .{ }^{a-c}$ Means with unlike letters are different $(P<$ $0.06)$ for isotrichids $(\mathrm{SE}=14.4) ;{ }^{\mathrm{e}-\mathrm{h}}$ means with unlike letters are different $(P<0.09)$ for entodiniomorphids $(\mathrm{SE}=4.0)$.

Relatively little is known about chemotaxis to sugars compared with chemotaxis to peptides by nonrumen ciliates. Sugar-binding sites on cellular membranes might be relatively nonspecific in Tetrahymena (Leick et al., 2003). The potential for mannose to block chemotaxis in that study and with planktonic protists (Wootton et al., 2007) and the observation that mannose is toxic to rumen isotrichids (Williams and Coleman, 1992) deserves further attention.

\section{Experiment 3: Chemotaxis to Peptides of Soy, Protozoal, or Bacterial Origin}

The UN treatment was not used in polynomial contrasts but is presented in Figure 6 for relative comparison of responses by entodiniomorphids and isotrichids to peptide treatments. The main effect mean (averaged over peptide sources) for the 1,000 mg/L, when expressed as a percentage of UN, were similar for isotrichids (71\%) and entodiniomorphids (80\%).

Because of an interaction $(P<0.05)$ between protein source and peptide concentration for isotrichid populations, contrasts for peptide concentration were evaluated for each peptide source (Figure 6A). Chemotaxis by isotrichids toward soy or bacterial peptides increased linearly $(P<0.05)$ when peptide increased from 0 to $1,000 \mathrm{mg} / \mathrm{L}$. However, for protozoal peptides, a cubic $(P<0.05)$ response was detected, apparently because of greater chemotaxis toward lower concentrations of protozoal peptides. Counts in sealed capillary tubes were much less than those in UN (Figure 6A), whereas the opposite occurred for glucose or xylose (Figure $5 \mathrm{~A})$. Isotrichids are regarded as being less predatory to bacteria than are entodiniomorphids (Belanche et al., 2012). Subsequent work reported by Diaz et al. (2014) documented chemorepellency by isotrichids away from soy peptides at $1,000 \mathrm{mg} / \mathrm{L}$. Tetrahymena, a nonrumen ciliate genus, can be chemoattracted or repelled by different peptides, depending on concentration and possibly profile of AA (Köhidai et al., 2003a).

We detected no interaction $(P>0.10)$ between peptide source and concentration for entodiniomorphids, so main effect means were compared for peptide source, and polynomial contrasts for peptide concentration were performed over main effect means of peptide source (Figure 6B). Main effect means (averaged over peptide concentration) for entodiniomorphid chemotaxis were greater $(P<0.05)$ for soy peptides than for bacterial peptides or protozoal peptides. Main effect means (averaged over peptide treatment) had both linear and cubic contrasts $(P<0.05)$ with respect to peptide concentration. The cubic responses without significant quadratic contrasts demonstrate that increasing peptide gradient had variable responses with respect to peptide concentration. Diaz et al. (2014) determined that mixed entodiniomorphid chemotaxis to $1,000 \mathrm{mg} / \mathrm{L}$ of soy peptides was generally unresponsive to various inhibitors, so differential responses by subpopulations of these mixed entodiniomorphids is a likely explanation to the cubic response.

\section{Experiment 4: Preincubation in PUFA and Chemotaxis to Glucose}

$\log _{10}$ counts in UN capillary tubes were analyzed to test effects of incubation time, effect of lipids from Liposyn, and their interaction on protozoal densities in beakers. No interaction $(P>0.10)$ for PUFA $\times$ time was detected for isotrichid counts. The main effect means (averaged over both times) decreased linearly $(P=0.01)$ with increasing PUFA concentration (Figure 7A). The $\log _{10}$ counts in the sealed tubes were covariate-adjusted for counts in UN to evaluate chemosensory behavior independent of decreased cell counts in beakers (Figure 7B). Isotrichids decreased chemotaxis to a nadir with increasing concentrations of PUFA (quadratic response, $P<0.05$; linear, $P>0.10$ ) but remained constantly chemotactic toward glucose (main effect of saline vs. glucose, $P<0.05$ ), and sealed capillary tube treatment did not interact with PUFA concentrations $(P>0.10)$.

We detected an interaction $(P=0.01)$ for PUFA dosage rate with time for entodiniomorphids in the UN capillary tubes, so polynomial contrasts were done at 


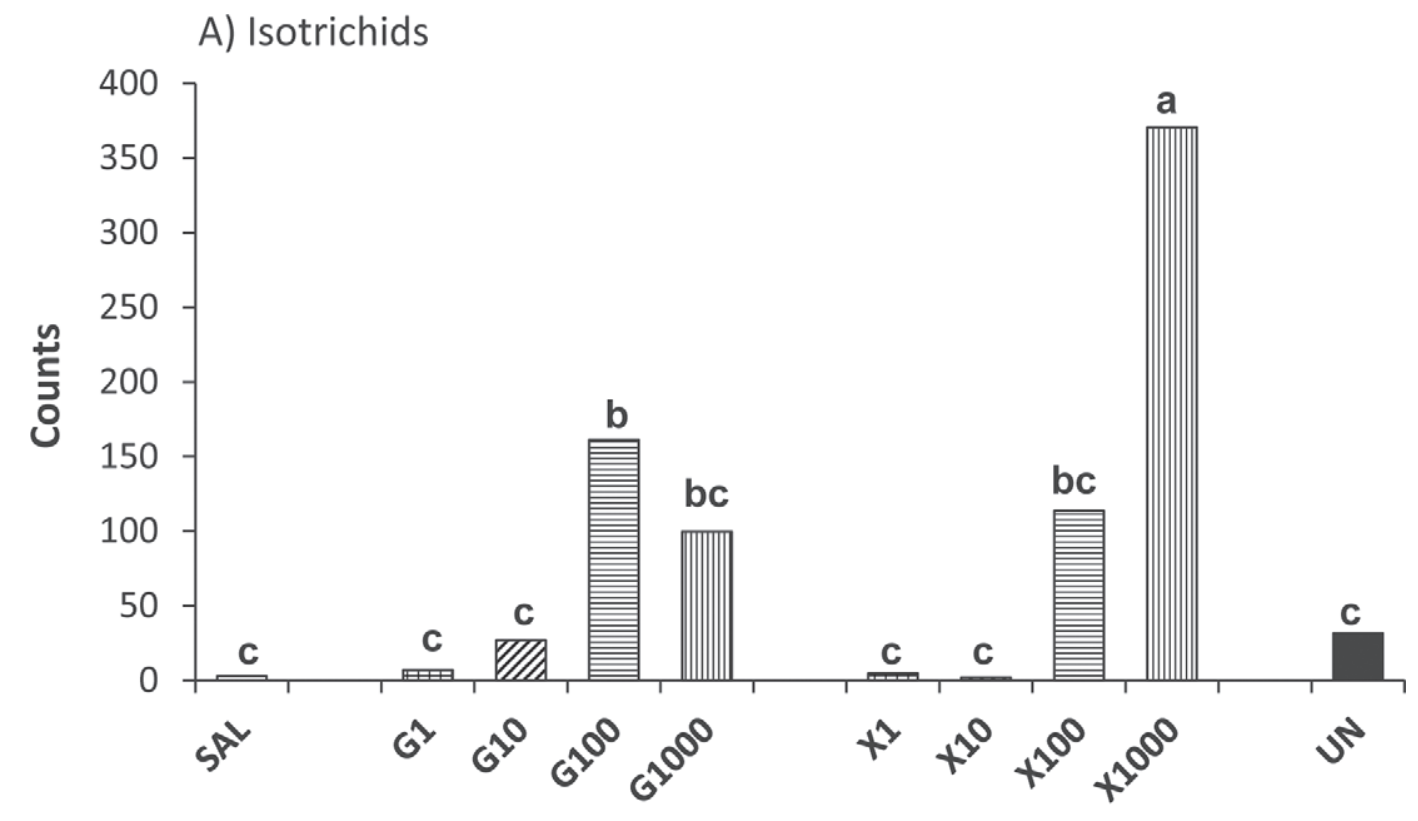

B) Entodiniomorphids

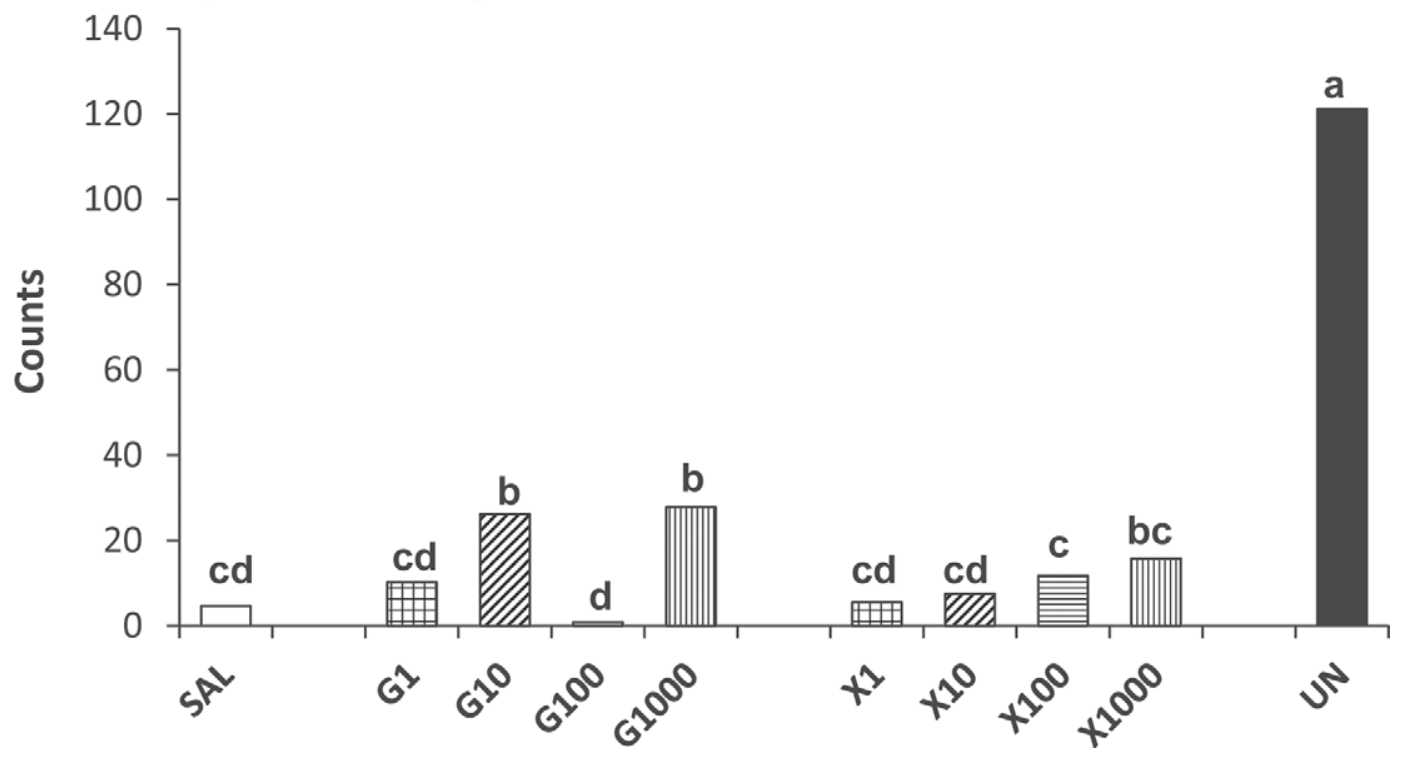

Figure 5. Counts of mixed isotrichids (panel A) and entodiniomorphis (panel B) in capillary tubes filled with saline (SAL) or saline containing glucose (G) or xylose (X) at 1, 10, 100, or 1,000 $\mathrm{m} M$ before sealing (G1 to G1000 and X1 to X1000) or in empty and unsealed (UN) capillary tubes in experiment $2 .{ }^{\mathrm{a}-\mathrm{c}}$ Means with unlike letters are different $(P \leq 0.06)$ for isotrichids $(\mathrm{SE}=46.6)$; ${ }^{\mathrm{a}-\mathrm{d}}$ means with unlike letters are different $(P \leq 0.08)$ for entodiniomorphids $(\mathrm{SE}=5.5)$.

both 3 and $6 \mathrm{~h}$. At $3 \mathrm{~h}$, increasing PUFA concentration decreased counts at a decreasing rate, with both linear and quadratic responses $(P<0.01)$; however, at $6 \mathrm{~h}$, counts decreased linearly $(P<0.01$; $\mathrm{Qu}$ was $P$ $>0.20$ ) with increasing PUFA concentrations (Figure 8A). Oldick and Firkins (2000) reported that protozoal counts decreased linearly with increasing unsaturation of supplemental dietary fat. $\log _{10}$ counts of entodiniomorphids inside sealed capillary tubes containing saline and glucose were covariateadjusted for the respective UN tubes. We observed a beaker PUFA concentration $\times$ sealed capillary treatment $\times$ time interaction $(P<0.05)$. At $3 \mathrm{~h}$, the main effect mean was greater $(P<0.01)$ for chemotaxis to glucose compared with random swimming into saline (Figure 8B). At $6 \mathrm{~h}$, the interaction $(P<0.01)$ between 


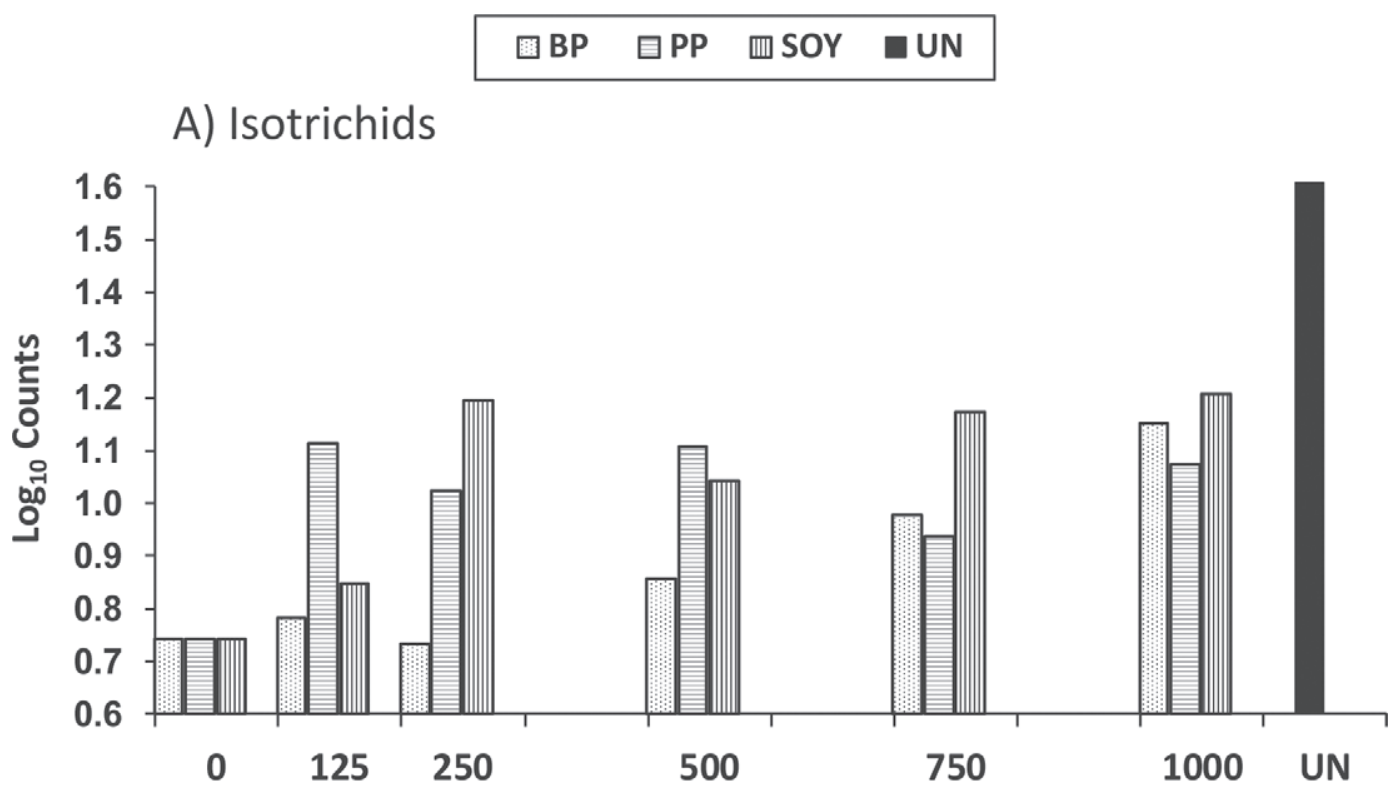

B) Entodiniomorphids

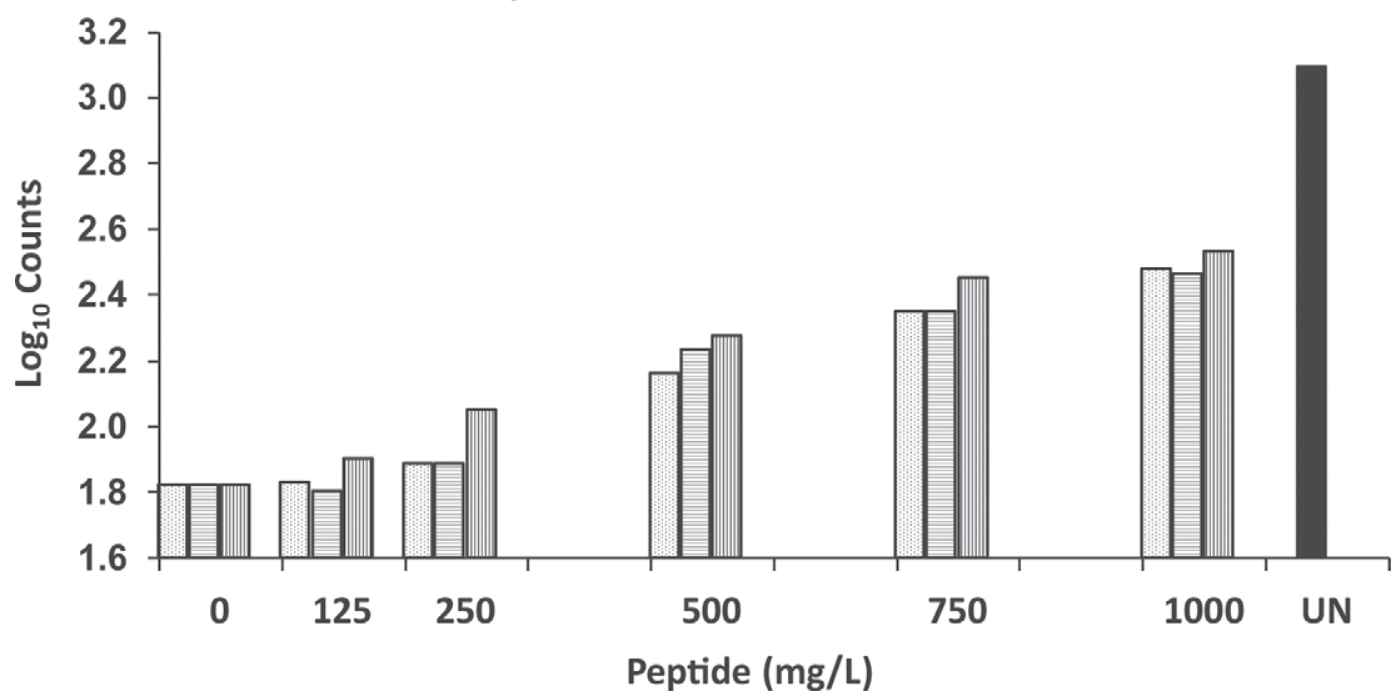

Figure 6. $\log _{10}$ counts of mixed isotrichids (panel A) or entodiniomorphids (panel B) in capillary tubes filled with saline or saline plus different hydrolyzed peptide sources (soy protein, SOY; protozoal protein, PP; or bacterial protein, BP) at different concentrations before sealing or in empty and unsealed (UN) capillary tubes in experiment 3. For isotrichids (panel A), there was a peptide source $\times$ concentration interaction $(P<0.05$; SE $=0.15)$. Peptide concentration was linear $(P<0.05)$ for BP, cubic $(P<0.05)$ for PP, and linear $(P<0.05)$ for SOY (all other contrasts were $P>0.10)$. For entodiniomorphids (panel B), there was no peptide source $\times$ peptide concentration interaction $(P>0.10 ; \mathrm{SE}=$ 0.16). Main effects means (averaged over peptide concentration) of $\mathrm{BP}$ and $\mathrm{PP}$ were not different $(P>0.10)$ from each other, but both were different $(P<0.05)$ from SOY. The main effect of peptide concentration (averaged over peptide source) was linear $(P<0.05)$ and cubic $(P<0.05)$.

PUFA and presence of glucose was explained by a cubic $(P<0.01)$ response to PUFA for the saline treatments without effect $(P>0.10)$ for any contrasts for the glucose sealed capillary tube treatments (Figure 8C).

Although isotrichid populations were inhibited by fat (i.e., decreased counts in UN treatments), chemotaxis to $1,000 \mathrm{~m} M$ glucose was unchanged (i.e., covariateadjusted for UN). In contrast, chemotaxis by entodini- omorphids in the presence of PUFA was more complex. Entodiniomorphids tended to recover the depressed chemotaxis to capillary tubes containing glucose when incubated with increasing concentrations of PUFA in beakers. Unsaturated fat might be directly toxic to entodiniomorphids or could be indirectly toxic by inhibiting chemotaxis and substrate acquisition. Production of lysophosphatidic acid (degradation product 


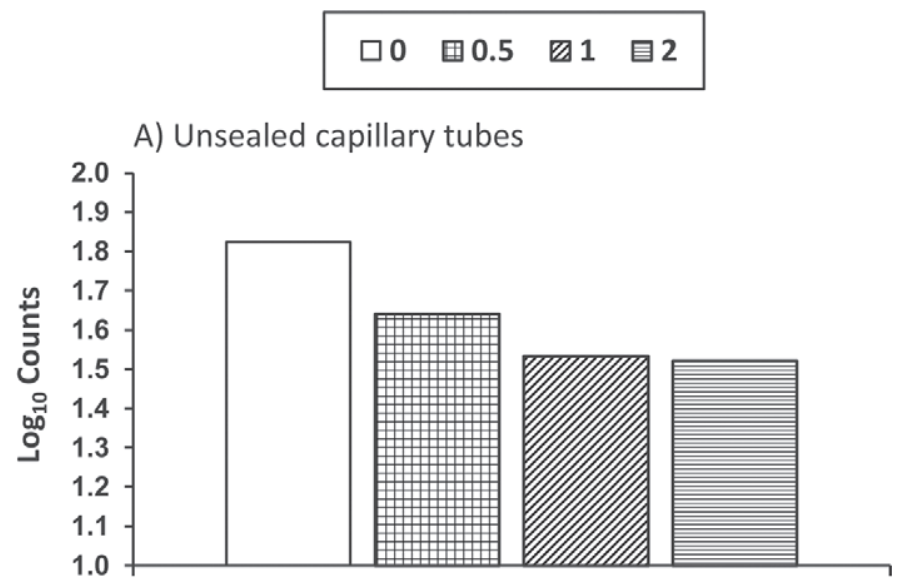

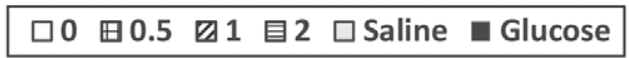

B) Sealed capillary tubes

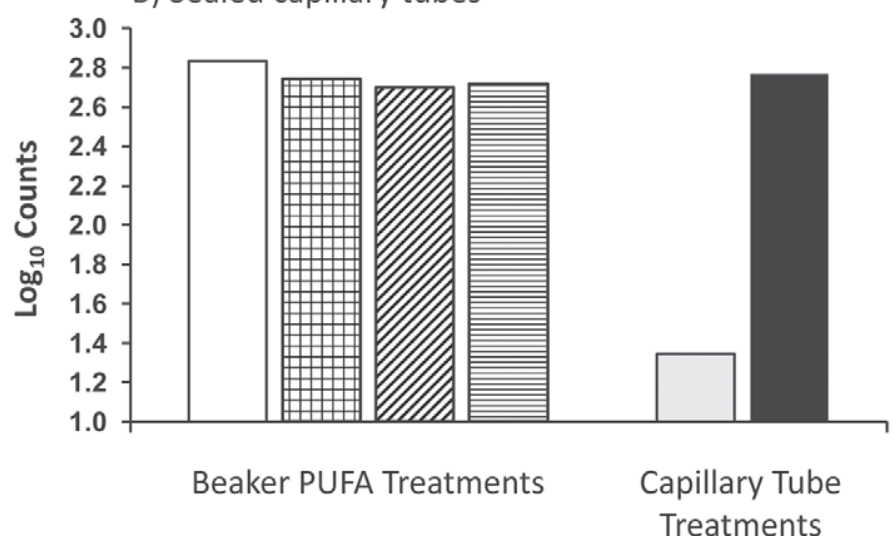

Figure 7. $\log _{10}$ counts of isotrichids in capillary tubes placed in beakers incubated with $0,0.5,1.0$, or $2.0 \%$ PUFA for 3 or $6 \mathrm{~h}$ in experiment 4. Panel A depicts the empty and unsealed (UN) capillary tubes placed in beakers. We detected no beaker PUFA treatment $\times$ time interaction $(P>0.10)$. Main effect means for PUFA treatments are presented (averaged over 3 and $6 \mathrm{~h}$ ). There was a linear $(P=0.01)$ decrease with increasing PUFA concentration without quadratic or cubic responses $(P>0.10 ; \mathrm{SE}=0.13)$. For panel $\mathrm{B}$, counts in capillary tubes containing saline or $1,000 \mathrm{~m} M$ of glucose before sealing were covariate-adjusted to the counts in the respective UN capillary tubes. There was no beaker PUFA concentration $\times$ time interaction $(P>0.10)$ or main effect of time $(P>0.10)$. Main effect means for beaker PUFA treatments (averaged over capillary tube treatments; left side) and capillary tube treatments (averaged over beaker PUFA treatments; right side) are presented. We observed a quadratic $(P<0.05)$ response to PUFA concentration without linear or cubic responses $(P$ $>0.10 ; \mathrm{SE}=0.12)$. The main effect means of saline and glucose were different $(P<0.01 ; \mathrm{SE}=0.09)$.

of lysophosphatidyl choline) is a common eukaryotic chemoattractant (Lampert et al., 2011) and was proposed to blind ruminal protozoa toward glucose gradients. Dynamic $\mathrm{Ca}^{2+}$ gradients, partly controlled by phospholipase $\mathrm{C}$, are needed to sensitize chemotaxis by Tetrahymena pyriformis (Nam et al., 2009). Lyposin is a mixture of triglycerides and phospholipids; hydrolysis of either to diacylgycerol could mimic a prolonged

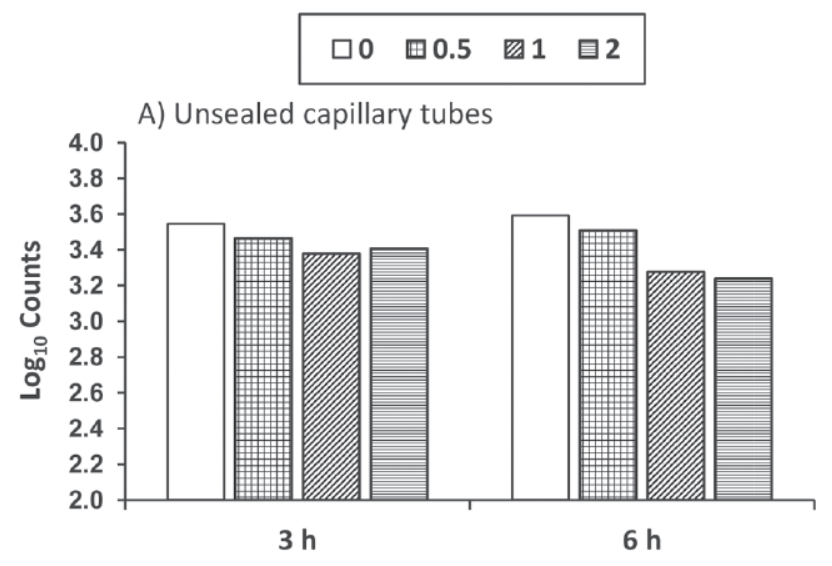

B) Sealed capillary tubes, $3 \mathrm{~h}$
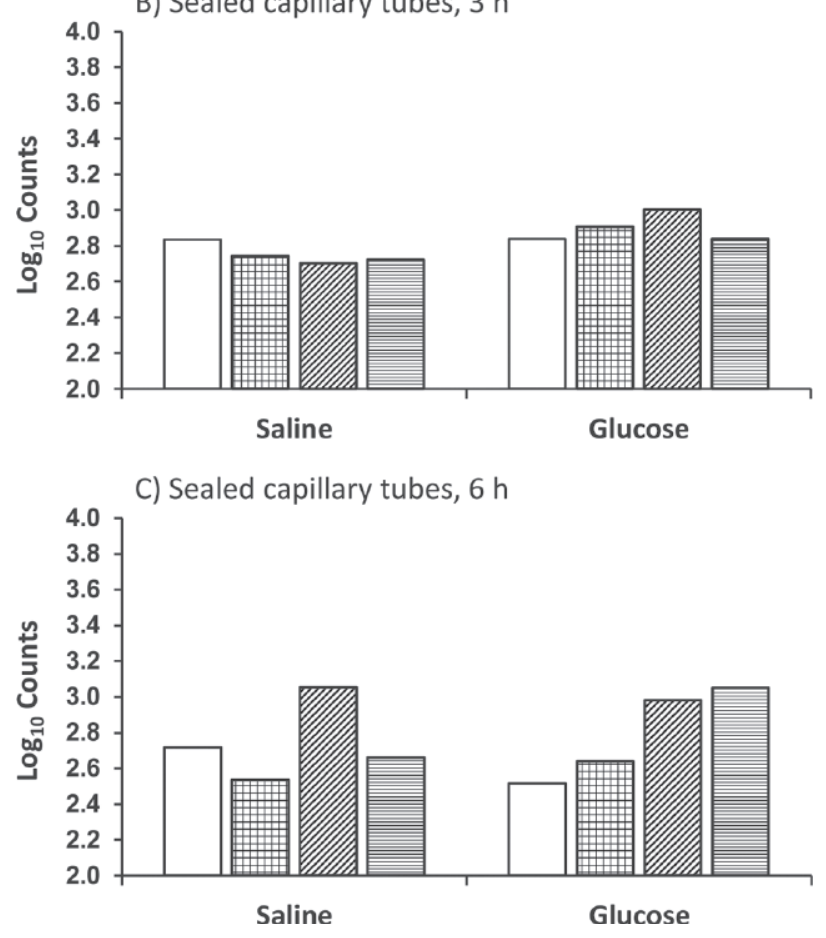

Figure 8. $\log _{10}$ counts of entodiniomorphids in capillary tubes placed in beakers incubated with $0,0.5,1.0$, or $2.0 \%$ PUFA for 3 or $6 \mathrm{~h}$ in experiment 4. Panel A depicts the empty and unsealed (UN) capillary tubes placed in beakers. We observed a beaker PUFA concentration $\times$ time interaction $(P=0.01)$. At $3 \mathrm{~h}$, we detected linear $(P<0.05)$ and quadratic $(P<0.05)$ responses to beaker PUFA concentration without cubic response $(P>0.10 ; \mathrm{SE}=0.07)$; at $6 \mathrm{~h}$, there was only a linear response $(P<0.05)$ without quadratic or cubic responses $(P>0.10 ; \mathrm{SE}=0.21)$. In panels $\mathrm{B}$ and $\mathrm{C}$, counts in sealed capillary tubes were covariate-adjusted to the counts in the respective UN capillary tubes. We detected a beaker PUFA treatment $x$ sealed capillary tube treatment $\times$ time interaction $(P<0.05)$. In panel $\mathrm{B}$, at $3 \mathrm{~h}$, there was no beaker PUFA treatment $\times$ capillary tube interaction $(P>0.10)$. The main effect means of saline and glucose (averaged over PUFA treatment) were different $(P<0.01)$. Linear, quadratic, and cubic contrasts for beaker PUFA concentration were $P>0.10$. In panel $\mathrm{C}$, at $6 \mathrm{~h}$, there was a beaker PUFA treatment $\times$ sealed capillary tube treatment interaction $(P<0.01)$ but no main effect of capillary tube treatment $(P>0.10)$. For saline, we observed a cubic response $(P$ $<0.01 ; \mathrm{SE}=0.15)$ without linear or quadratic responses $(P>0.10)$ to beaker PUFA concentration. For glucose, all linear, quadratic, and cubic contrasts were $P>0.10(\mathrm{SE}=0.16)$. 
phospholipase $\mathrm{C}$ signal and thereby obscure chemotaxis. More work is needed to explain the variable responses of lipids to suppress protozoal abundance (Firkins et al., 2007).

\section{CONCLUSIONS}

Isotrichid protozoa increased chemotaxis toward increasing glucose concentration when the cow was fasted; in contrast, chemotaxis maximized at an intermediate glucose concentration $(100 \mathrm{~m} M)$ when rumen samples were collected from fed cows. Entodiniomorphids exhibited chemotaxis to a lesser degree, regardless of feeding status of the cows, but to similar glucose concentrations as did isotrichids. Entodiniomorphids exhibited dose-responsive chemotaxis to peptides, regardless of peptide source, affirming their importance in ruminal proteolysis. The constant chemotaxis to glucose and peptides by entodiniomorphids supports a continual attraction to the potentially digestible particulate fraction for ingestion of disintegrating starch granules and fibrous particulates along with bacteria, which also are predominantly in the particulate fraction of rumen digesta. Lipids might be inhibitory to protozoa by disrupting membrane integrity but appeared not to inhibit entodiniomorphid chemoattraction toward a glucose gradient. Efforts to suppress protozoa-mediated intraruminal recycling of microbial $\mathrm{N}$ or methanogenesis from protozoa-associated archaea should consider the role of chemotaxis in protozoal ecology.

\section{ACKNOWLEDGMENTS}

Research was supported by state and federal funds appropriated to the Ohio Agricultural Research and Development Center, The Ohio State University. Research funds were provided by the USDA National Research Initiative Grant 2008-35206-18847. This paper is manuscript number 20/13AS.

\section{REFERENCES}

Abe, M., T. Iriki, N. Tobe, and H. Shibui. 1981. Sequestration of holotrich protozoa in the reticulo-rumen of cattle. Appl. Environ. Microbiol. 41:758-765.

Bach, A., S. Calsamiglia, and M. D. Stern. 2005. Nitrogen metabolism in the rumen. J. Dairy Sci. 88(E. Suppl.):E9-E21.

Bauchop, T., and R. T. Clarke. 1976. Attachment of the ciliate Epidinium Crawley to plant fragments in the sheep rumen. Appl. Environ. Microbiol. 32:417-422.

Belanche, A., G. de la Fuente, J. M. Moorby, and C. J. Newbold. 2012. Bacterial protein degradation by different rumen protozoal groups. J. Anim. Sci. 90:4495-4504.

Belzecki, G., R. Miltko, and T. Michalowski. 2004. Why does the establishment of the starch preferring Entodinium caudatum in the rumen decrease the numbers of the fibrolytic ciliate Eudiplodinium maggii? Folia Microbiol. (Praha) 49:139-142.
Coleman, G. S., and J. I. Laurie. 1974. The metabolism of starch, glucose, amino acids, purines, pyrimidines and bacteria by three Epidinium spp. isolated from the rumen. J. Gen. Microbiol. $85: 244-256$.

Coleman, G. S., and J. I. Laurie. 1977. The metabolism of starch, glucose, amino acids, purines, pyrimidines and bacteria by the rumen ciliate Polyplastron multivesiculatum. J. Gen. Microbiol. 98:29-37.

Dehority, B. A. 1984. Evaluation of subsampling and fixation procedures used for counting rumen protozoa. Appl. Environ. Microbiol. 48:182-185.

Dehority, B. A. 2003. Rumen Microbiology. Nottingham University Press, Nottingham, UK.

Dehority, B. A., and P. A. Tirabasso. 1989. Factors affecting the migration and sequestration of rumen protozoa in the family Isotrichidae. J. Gen. Microbiol. 135:539-548.

Diaz, H. L., K. N. Barr, K. R. Godden, J. E. Plank, I. Zapata, A. N. Schappacher, M. P. Wick, and J. L. Firkins. 2014. Eukaryotic inhibitors or activators elicit responses to chemosensory compounds by ruminal isotrichid and entodiniomorphid protozoa. J. Dairy Sci. 97:2254-2269. http://dx.doi.org/10.3168/jds.2013-7698.

Dijkstra, J., J. France, and D. R. Davies. 1998. Different mathematical approaches to estimating microbial protein supply in ruminants. J. Dairy Sci. 81:3370-3384.

Firkins, J. L. 1996. Maximizing microbial protein synthesis in the rumen. J. Nutr. 126:1347S-1354S.

Firkins, J. L., S. K. R. Karnati, and Z. Yu. 2008. Linking rumen function to animal response by application of metagenomics techniques. Aust. J. Exp. Agric. 48:711-721.

Firkins, J. L., and Z. Yu. 2006. Characterisation and quantification of the microbial populations in the rumen. Pages 19-54 in Ruminant Physiology, Digestion, Metabolism and Impact of Nutrition on Gene Expression, Immunology and Stress. K. Sejrsen, T. Hvelplund, and M. O. Nielsen, ed. Wageningen Academic Publishers, Wageningen, the Netherlands.

Firkins, J. L., Z. Yu, and M. Morrison. 2007. Ruminal nitrogen metabolism: Perspectives for integration of microbiology and nutrition for dairy. J. Dairy Sci. 90(E. Suppl.):E1-E16.

Hook, S. E., J. Dijkstra, A.-D. G. Wright, B. W. McBride, and J. France. 2012. Modeling the distribution of ciliate protozoa in the reticulo-rumen using linear programming. J. Dairy Sci. 95:255265.

Jarvis, B. D. W., and R. E. Hungate. 1968. Factors influencing agnotobiotic cultures of the rumen ciliate, Entodinium simplex. Appl. Microbiol. 16:1044-1052.

Karnati, S. K. R., J. T. Sylvester, S. M. Noftsger, Z. Yu, N. R. StPierre, and J. L. Firkins. 2007. Assessment of ruminal bacterial populations and protozoal generation time in cows fed different methionine sources. J. Dairy Sci. 90:798-809.

Köhidai, L., O. Láng, and G. Csaba. 2003a. Chemotactic-range-fitting of amino acids and its correlations to physicochemical parameters in Tetrahymena pyriformis - Evolutionary consequences. Cell. Mol. Biol. 49:OL487-OL495.

Kohidai, L., K. Török, E. Illyés, J. Tamási, F. Sebestyén, O. Láng, G. Csaba, and F. Hudecz. 2003b. Characterization of chemotactic ability of peptides containing N-formyl-methionyl residues in Tetrahymena fMLP as a targeting ligand. Cell Biol. Int. 27:695-700.

Lampert, T. J., K. D. Coleman, and T. M. Hennessey. 2011. Chemoattraction to lysophosphatidic acid does not require a change in membrane potential in Tetrahymena thermophila. Cell Biol. Int. 35:519-528.

Leick, V., and F. Chen. 2004. Chemosensory behaviour and ciliary cyclic GMP-dependent protein kinase in Tetrahymena thermophila. Eur. J. Protistol. 40:303-312.

Leick, V., C. G. Iverson, J. D. Olesen, and T. C. Bøg-Hansen. 2003 Concanavalin A and the motile behaviour of the ciliate Tetrahymena. Eur. J. Protistol. 39:390-393.

Mah, R. A. 1964. Factors influencing the in vitro culture of the rumen ciliate Ophryoscolex purkynei Stein. J. Protozool. 11:546-552.

Michalowski, T., K. Rybicka, K. Wereszka, and A. Kasperowicz. 2001. Ability of the rumen ciliate Epidinium caudatum to digest and use 
crystalline cellulose and xylan for in vitro growth. Acta Protozool. 40:203-210.

Murphy, M. R., P. E. Drone Jr., and S. T. Woodford. 1985. Factors stimulating migration of holotrich protozoa into the rumen. Appl. Environ. Microbiol. 49:1329-1331.

Nam, S.-W., S.-T. Kim, K.-M. Lee, S. H. Kim, S. Kou, J. Lim, H. Hwang, M. K. Joo, B. Jeong, S. H. Yoo, and S. Park. 2009. NMethyl-D-aspartate receptor-mediated chemotaxis and $\mathrm{Ca}^{2+}$ signaling in Tetrahymena pyriformis. Protist 160:331-342.

NRC. 2001. Nutrient Requirements of Dairy Cattle. 7th rev. ed. ed. Natl. Acad. Sci., Washington, DC.

Oldick, B. S., and J. L. Firkins. 2000. Effects of degree of fat saturation on fiber digestion and microbial protein synthesis when diets are fed twelve times daily. J. Anim. Sci. 78:2412-2420.

Onodera, R., and C. Henderson. 1980. Growth factors of bacterial origin for the culture of the rumen oligotrich protozoon, Entodinium caudatum. J. Appl. Bacteriol. 48:125-134.

Orpin, C. G. 1985. Association of rumen ciliate populations with plant particles in vitro. Microb. Ecol. 11:59-69.

Piwonka, E. J., J. L. Firkins, and B. L. Hull. 1994. Digestion in the rumen and total tract of forage-based diets with starch or dextrose supplements fed to Holstein heifers. J. Dairy Sci. 77:1570-1579.

Reveneau, C., S. K. R. Karnati, E. R. Oelker, and J. L. Firkins. 2012. Interaction of unsaturated fat or coconut oil with monensin in lactating dairy cows fed twelve times daily. I. Protozoal abundance, nutrient digestibility, and microbial protein flow to the omasum. J. Dairy Sci. 95:2046-2060.

Russell, J. B. 2002. Rumen Microbiology and its Role in Ruminant Nutrition. Cornell University, Ithaca, NY.
Skillman, L. C., A. F. Toovey, A. J. Williams, and A.-D. G. Wright. 2006. Development and validation of a real-time PCR method to quantify rumen protozoa and examination of variability between Entodinium populations in sheep offered a hay-based diet. Appl. Environ. Microbiol. 72:200-206.

Sylvester, J. T., S. K. R. Karnati, Z. Yu, M. Morrison, and J. L. Firkins. 2004. Development of an assay to quantify rumen ciliate protozoal biomass in cows using real-time PCR. J. Nutr. 134:3378-3384.

Sylvester, J. T., S. K. R. Karnati, Z. Yu, C. J. Newbold, and J. L. Firkins. 2005. Evaluation of a real-time PCR assay for measuring the ruminal pool and duodenal flow of protozoal nitrogen. J. Dairy Sci. 88:2083-2095.

Walker, N. D., C. J. Newbold, and R. J. Wallace. 2005. Nitrogen metabolism in the rumen. Pages 71-115 in Nitrogen and Phosphorus Nutrition of Cattle. E. Pfeffer and A. Hristov, ed. CABI Publishing, Cambridge, MA

Wang, W., L. M. Shor, E. J. LeBoeuf, J. P. Wikswo, and D. S. Kosson. 2005. Mobility of protozoa through narrow channels. Appl. Environ. Microbiol. 71:4628-4637.

Williams, A. G., and G. S. Coleman. 1992. The Rumen Protozoa. Springer-Verlag, New York, NY.

Williams, A. G., and G. S. Coleman. 1997. The rumen protozoa. Pages 73-139 in The Rumen Microbial Ecosystem. P. N. Hobson and C. S. Stewart, ed. Blackie Academic \& Professional, New York, NY.

Wootton, E. C., M. V. Zubkov, D. H. Jones, R. H. Jones, C. M. Martel, C. A. Thornton, and E. C. Roberts. 2007. Biochemical prey recognition by planktonic protozoa. Environ. Microbiol. 9:216-222. 